\title{
Spatial and temporal aggregation of Oryzaephilus surinamensis from Peninsular Malaysia
}

\author{
Syed Ahmad Syarifah Zulaikha and Salmah Yaakop* \\ ${ }^{1}$ Centre for Insect Systematics, Department of Biological Science and Biotechnology, Faculty of Science and Technology, \\ Universiti Kebangsaan Malaysia (UKM), 43600 Bangi, Selangor, Malaysia \\ *Corresponding author's e-mail: salmah78@ukm.edu.my
}

\begin{abstract}
The saw-toothed grain beetle, Oryzaephilus surinamensis (Linnaeus) is a secondary pest of rice grains and other stored products. Lack of information on the population abundance, spatial, and temporal distribution of $O$. surinamensis rendered the management control strategy of this pest species less effective. The objective of this study was to investigate the abundance, spatial and temporal pattern of $O$. surinamensis populations from nine rice warehouses in three zones of Peninsular Malaysia (i.e., the northern, central and southern zones) for three continuous months. The results showed that the abundance of $O$. surinamensis populations varied significantly $(\mathrm{p}<0.05, \mathrm{p}=0.00)$ between zones, with the highest abundance for this species (69\%) recorded from the Klang District, in the central zone, followed by Pasir Gudang (27\%) in the southern zone, and Seberang Prai (4\%) in the northern zone. The patterns of population abundance also showed significant differences between months, $\mathrm{p}<0.05$ ( $\mathrm{p}$-value $=0.00-0.011$ ) between all the warehouses. The factors that could be associated with the highest abundance of the pest were attributed to poor sanitation at the warehouses and inconsistency in the fumigation regime. For the spatial distribution analysis, SADIEShell_122 and Surfer8 software were applied. The distribution patterns of $O$. surinamensis populations varied significantly in all the warehouses, being significantly aggregated at $\mathrm{p}<0.05(\mathrm{p}=0.0385-0.0513)$ and $\mathrm{I}_{\mathrm{a}}>1.0$ (1.212-1.579), whilst being non-significantly and randomly distributed at $\mathrm{p}>0.05(\mathrm{p}=0.1154-0.91032)$ and $\mathrm{I}_{\mathrm{a}}>1.0(0.852-$ 0.929). The significance of the aggregation might be due to the rapidly changing volume of the rice stock caused by the active and rapid turnover of the storage inventory. The results obtained were very valuable and informative in managing $O$. surinamensis infestation of stored rice by incorporating the spatial and temporal information of the pest populations in the management strategy for improving the rice and other stored products.
\end{abstract}

Keywords: storage pest, behavior, movement, rice storage, Malaysia.

\section{INTRODUCTION}

Oryzaephilus surinamensis (Linnaeus), or commonly known as the saw-toothed grain beetle, is one of the most ubiquitous storage pests worldwide (Rossiter et al., 2001; Hashem et al., 2012; Syarifah Zulaikha et al., 2018). Both the adult and larva of this species are known to be cosmopolitan (Highland, 1991; Mowery et al., 2002) due to their ability to attack and infest a large variety of food products such as flour (Ogebegbe and Edoreh, 2014), chocolates, nuts (Barnes, 2002), dried fruits and cereals. Oryzaephilus surinamensis is also known as a secondary pest which plays its role in infesting and damaging the broken food kernel affected by primary pests such as Sitophilus spp. and Rhyzopertha dominica (Trematerra and Throne, 2012). Larvae and adults of $R$. dominica would infest grain products causing broken kernels, powdery residues and pungent odour (Toews et al., 2006), which were then attacked by the secondary pests and fungi (Shah and Khan, 2014).

Several earlier studies have been conducted to measure the infestation rate of storage pests and the diversity, as well as abundance of the pest species over the three-month study duration. For example, weight losses of up to $40 \%$ of brown rice were reported by Sittisuang and Imura (1987) after three months of exposure to $R$. dominica. Besides that, the favorable conditions of the warehouses with optimal temperature and humidity could provide the best shelter for storage pests to thrive in (Reichmuth, 2000). Of greater concern was the fact that these conditions could cause interand intra-dispersal of the pest species through grain transportation and marketing networks (Hernandez Nopsa et al. 2015).

According to Arbogast et al., (2000a), spatial and temporal distribution analysis is a fundamental study for the effective

Syarifah Zulaikha, S.A. and S. Yaakop. Spatial and temporal aggregation of Oryzaephilus surinamensis from Peninsular Malaysia. Pak. J. Agri. Sci. 58:11231130.

[Received 28 Mar 2021; Accepted 2 Jul 2021; Published (online) 21 Sep 2021]

(c) (i) 
management system of storage pests. The main purpose of this study is to determine (by spatial and temporal mapping) the behavior and distribution of $O$. surinamensis in the warehouses and its association with biotic and abiotic factors. This is because the movement and population dynamics of the pests are largely influenced by factors such as the location and arrangement of the rice stacks, the layout and built structure of the different warehouses (Arbogast et al., 2000a; Reichmuth, 2000).

The foundation of an effective pest management programme through Integrated Pest Management (IPM) is an understanding of the pest ecology and behavior, and such understanding must be at an appropriate spatial and temporal scale suited for the pest species and the environment (Semeaoa et al., 2014). The ecological processes such as population dynamics, movement patterns and spatial distribution could be influenced by the structure of the landscape mosaic in which an organism lived. Stored-product pests occupy spatially and temporally fragmented habitats that can have profound impacts not only on their population dynamics, but also on our ability to monitor their populations and effectively target pest management. Therefore, the aim of this study is to determine the population abundance, spatial and temporal distribution of the pest, $O$. surinamensis over a three-month period in various parts of Peninsular Malaysia.

\section{MATERIALS AND METHODS}

Sampling location: A total of nine warehouses from three geographical zones in Peninsular Malaysia, i.e., the central part (Klang, namely A, B and C), the southern part (Pasir Gudang, namely M, N and O) and the northern part (Seberang Prai, namely X, Y and Z) had been randomly selected for the three-month study period to conduct sampling for the abundance, spatial and temporal distribution of $O$. surinamensis populations infesting stored rice. The main abiotic factors (temperature, humidity, $\mathrm{CO}_{2}$ concentration and light intensity) in all the warehouses were standardized and monitored.

Insect Sampling: The O. surinamensis individuals were sampled continuously by using the sticky traps for three months. A total of 24 traps (A4 sized) had been placed in each warehouse in four line transects with 6 plots at 5-meter intervals, and each transect was separated from the others at 10-meter intervals. The sticky traps were placed for 24 hours in the beginning of each month and were then replaced gradually during the three-month study period. All the traps were placed on the warehouse floor. Figure 2 shows the placement of the 24 sticky traps in every warehouse, with a total plot size of $25 \times 30 \mathrm{~m}$ and was standardized for all the warehouses.

Species Identification and Data Collection: The $O$. surinamensis had been identified morphologically by referring to the taxonomic key of Ferrer et al. (1995) using the stereomicroscope StemiD4 (Zeisz). The individuals of $O$. surinamensis were sampled and counted for the population abundance study, and for spatial and temporal distribution analysis.

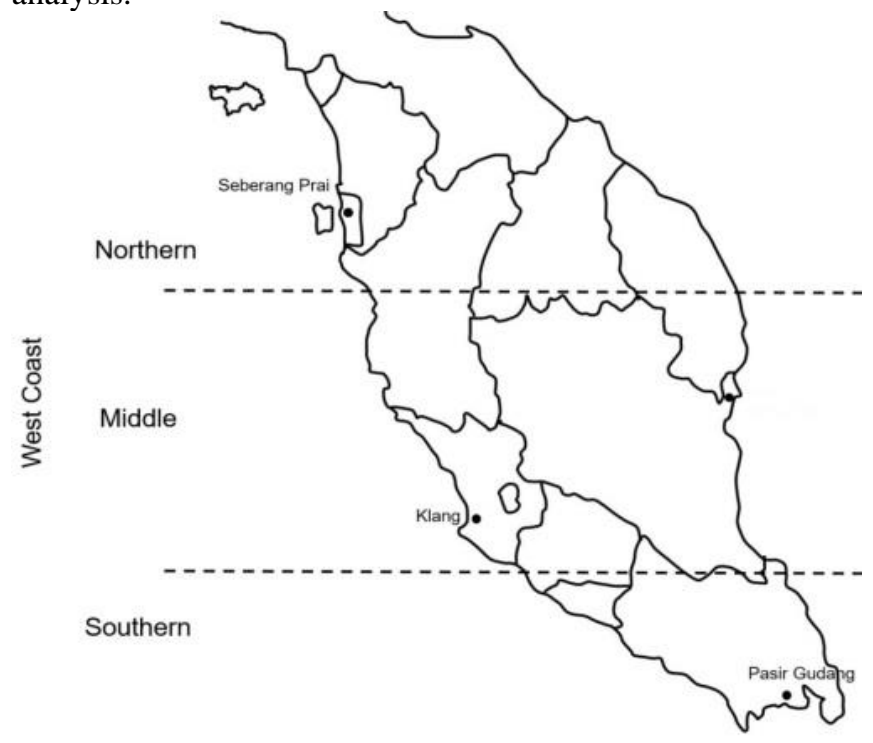

Figure 1. Localities of $O$. surinamensis collected from three geographical zones in Peninsular Malaysia

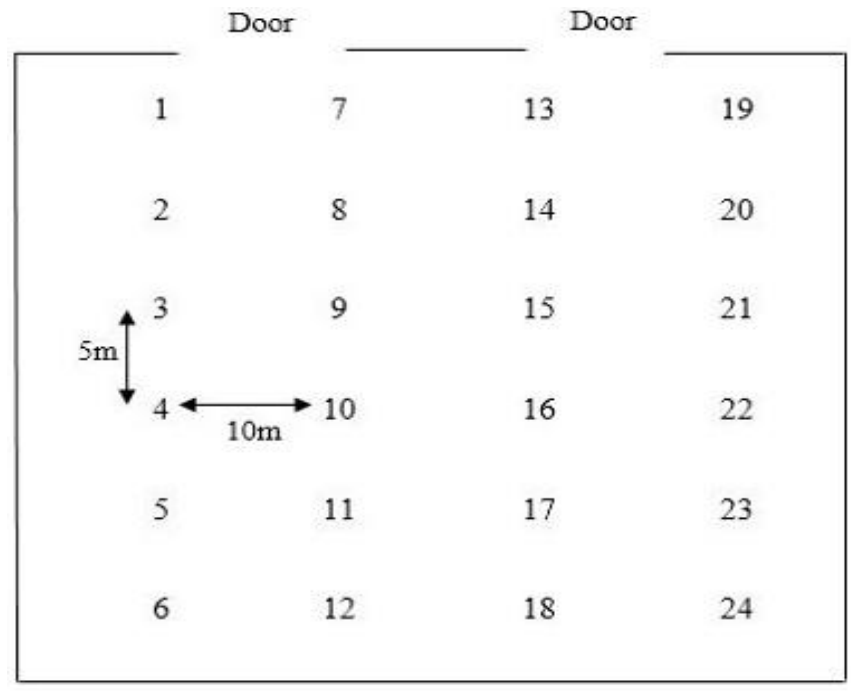

*1-24 is the number of sticky traps used

Figure 2. Illustration of the sticky trap placement in the warehouses

Data Analysis: The significant abundance (p- value) of $O$. surinamensis between months for each warehouse was measured using one-way ANOVA, as well as the total abundance of this species over the three-month study duration at all the warehouses according to zones (Klang, Pasir Gudang and Seberang Prai).

Spatial and Temporal Distribution Analysis of $O$. surinamensis: The spatial analysis was carried out using the 
software SADIEShell_122 and Surfer8 (Golden software, Golden, CO, USA). The $\mathrm{x}$ and $\mathrm{y}$ coordinates represent the position of the traps, while the $\mathrm{z}$ coordinates ( 24 points) represent the total number of $O$. surinamensis captured in each trap. The $\mathrm{Z}$ values produce the grid values which are used for the interpolation of contour maps by using the Kriging method (Lazzari et al., 2010). Spatial analysis introduces a way for the entomologist in the management of spatial distribution of stored product pests in warehouses, and this technique has been used in precise monitoring and control method on moths and beetle pests (Arbogast et al., 2000a, b; Sciarretta et al., 2001).

\section{RESULTS}

Population Abundance: The abundance of $O$. surinamensis populations varied significantly at $\mathrm{p}<0.05, \mathrm{p}=0.00$ according to the geographical zones, with the highest abundance of this species in the central part of Peninsular Malaysia (Klang, at $69 \%$ ), followed by the southern part (Pasir Gudang, at 27\%), and the lowest was in the northern part (Seberang Prai, at 4\%) (Figure 3).

The patterns of population abundance showed significant differences between months, $(p<0.05$, ( $p$-value=0.00-0.011). For the Klang area (B and $\mathrm{C}$ ), there were two warehouses that showed significant differences for the first and second months compared to the third month, whilst for the $\mathrm{M}$ and $\mathrm{N}$ warehouses in the Pasir Gudang area, the abundance pattern for the second month differed significantly compared to the first and third months. However, all the warehouses in Seberang Prai did not show any significant differences between months, $(\mathrm{p}>0.05$, ( $\mathrm{p}$-value=0.141-0.648) (Figures $4 \mathrm{a}$ to $4 \mathrm{c})$.
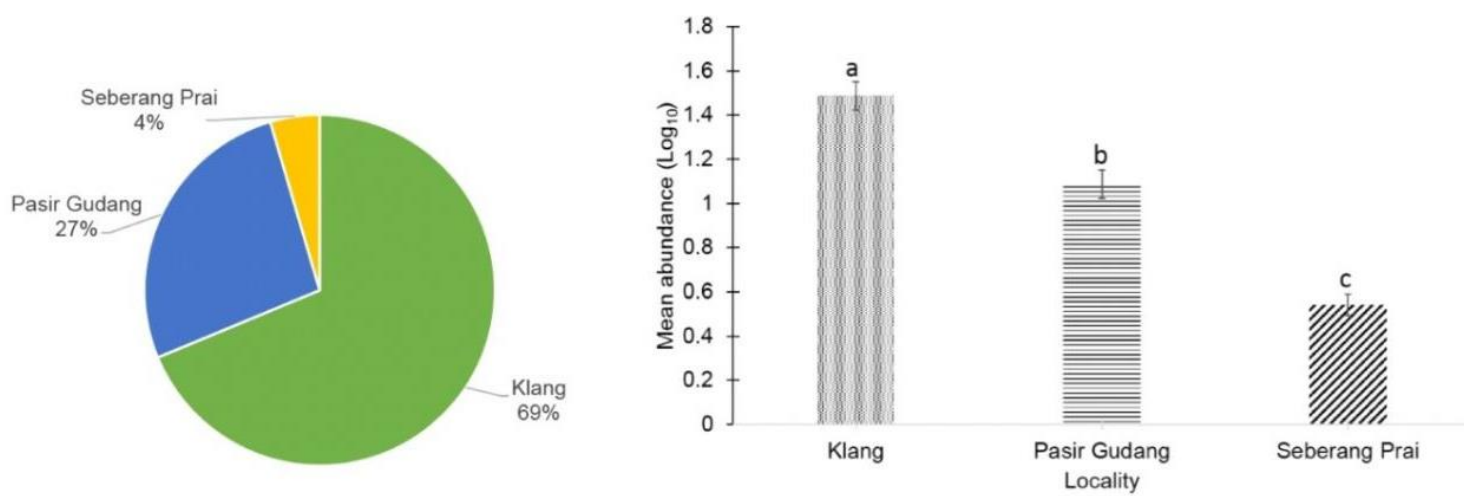

Figure 3. Composition of total abundance of $O$. surinamensis in three zones of Peninsular Malaysia
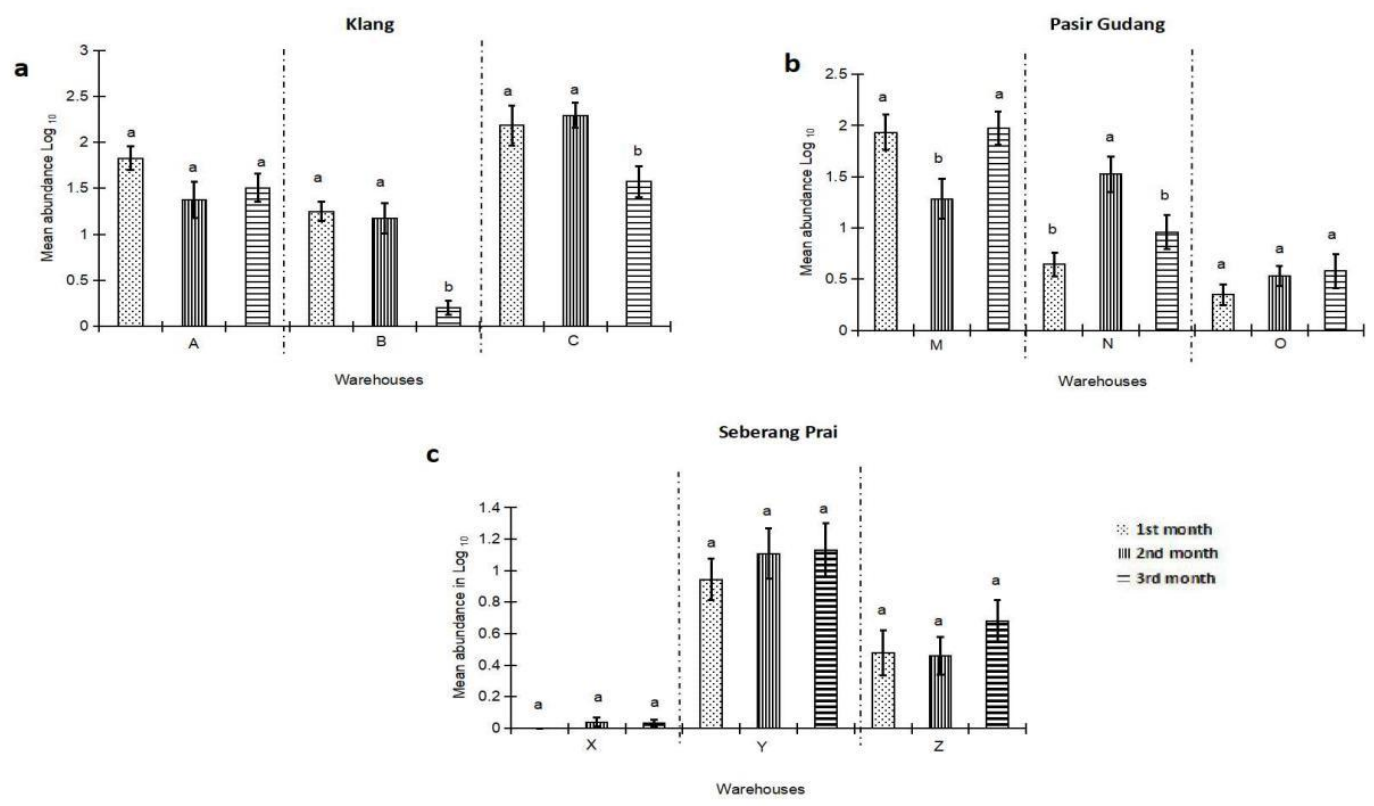

Figures 4a-c. Abundance of $O$. surinamensis in nine warehouses throughout the three-month period. 
Table 1. Aggregation index, cluster and space value for nine warehouses for the specific three-month duration.

\begin{tabular}{llll}
\hline Warehouses & Month & $\mathbf{P}_{\mathbf{a}}$ & $\mathbf{I}_{\mathbf{a}}$ \\
\hline $\mathrm{A}$ & June & 0.0897 & 1.293 \\
& July & $0.0128^{*}$ & 1.579 \\
$\mathrm{~B}$ & August & 0.5385 & 0.949 \\
& June & 0.3974 & 1.001 \\
$\mathrm{C}$ & July & 0.1923 & 1.102 \\
& August & 0.5897 & 0.937 \\
& June & 0.5769 & 0.929 \\
$\mathrm{M}$ & July & $0.0128^{*}$ & 1.579 \\
& August & 0.1154 & 1.300 \\
& September & 0.5385 & 0.959 \\
$\mathrm{~N}$ & October & $0.0128^{*}$ & 1.319 \\
& November & 0.2179 & 1.091 \\
& September & 0.1410 & 1.222 \\
$\mathrm{O}$ & October & $0.0128^{*}$ & 1.387 \\
& November & 0.2564 & 1.070 \\
$\mathrm{X}$ & September & $0.0256^{*}$ & 1.501 \\
& October & 0.1667 & 1.155 \\
& November & 0.7564 & 0.874 \\
$\mathrm{Y}$ & December & 0.9103 & 0.769 \\
& January & 0.7436 & 0.870 \\
$\mathrm{Z}$ & February & 0.8077 & 0.852 \\
$\mathrm{Z}$ & December & 0.5769 & 0.945 \\
& January & 0.3462 & 1.039 \\
& February & 0.8077 & 0.852 \\
& December & $0.0513^{*}$ & 1.212 \\
& January & $0.0128^{*}$ & 1.844 \\
& February & $0.0385^{*}$ & 1.482 \\
\hline
\end{tabular}

Legend: $\mathrm{P}_{\mathrm{a}}<0.05=$ significant distribution*; $\mathrm{I}_{\mathrm{a}}$ is a distribution pattern aggregated, random or regular; $\mathrm{I}_{\mathrm{a}}>1.0$ (aggregated); $\mathrm{I}_{\mathrm{a}}=1.0$ (random); $\mathrm{I}_{\mathrm{a}}<1.0$ (regular)
Spatial and Temporal Distribution: The spatial distribution during the three-month study duration of $O$. surinamensis populations in all the warehouses in three zones were significantly variable, either being aggregated or randomly distributed (Figures 5a to 5c, and Table 1). In Klang, the spatial pattern of $O$. surinamensis showed significantly aggregated distribution only in A and C warehouses in July, at $p<0.05(p=0.0128)$ and $I_{a}=1.579$. Meanwhile, the Pasir Gudang warehouses ( $\mathrm{M}$ and $\mathrm{N}$ ) showed significantly aggregated distribution in October at $\mathrm{p}<0.05\left(\mathrm{p}=0.0128\right.$ and $\mathrm{I}_{\mathrm{a}}$ $=1.319-1.387$, while warehouse $\mathrm{O}$ showed a similar pattern in September, at $\mathrm{p}<0.05(\mathrm{p}=0.0256)$ and $\mathrm{I}_{\mathrm{a}}=1.501$. Interestingly, the $\mathrm{Z}$ warehouse in Seberang Prai also showed significantly aggregated distribution in December, January and February at $\mathrm{p}=0.0128-0.0513$ and $\mathrm{I}_{\mathrm{a}}=1.212-1.844$ ), while the other two warehouses in this zone (i.e. $\mathrm{X}$ and $\mathrm{Y}$ ) showed a largely nonsignificant and randomly distributed pattern of $O$. surinamensis populations over the three-month period, at $\mathrm{p}>0.05\left(\mathrm{p}=0.3462-0.9103\right.$ and $\left.\mathrm{I}_{\mathrm{a}}=0.769-0.945\right)$.

\section{DISCUSSION}

According to Beckel et al. (2007), the significant increment of $O$. surinamensis infestation as a secondary pest of rice grain in the storage facilities was attributed to the increase of broken grains production, the damage occurring during the post-harvest handling by the mechanical equipment. The abundance of the pest species in the warehouse should be monitored precisely for better management and control strategy of the pest species. Nine warehouses located within three geographical zones, i.e. northern, central, and southern parts of Peninsular Malaysia were randomly studied for a three-month period. However, the abiotic parameters such as a
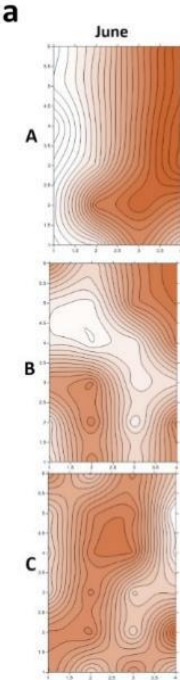

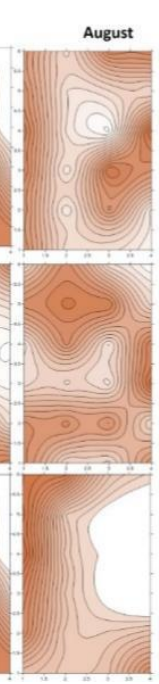

b

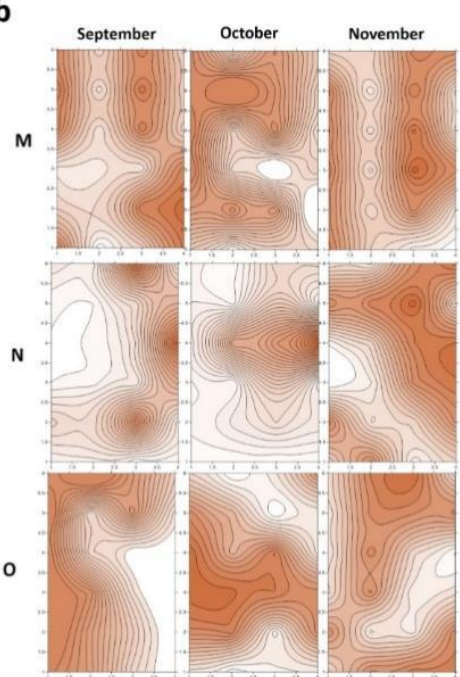

c

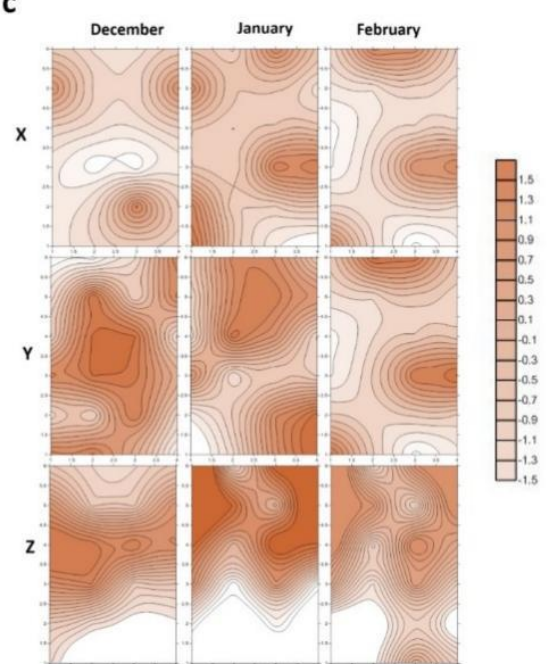

Figures 5a-c. Spatial distribution pattern of $O$. surinamensis in the rice warehouses observed for three months using the Krigging method; A, Klang, B, Pasir Gudang, C, Seberang Prai. 
ambient temperature, relative humidity and $\mathrm{CO}_{2}$ concentration were not monitored because the dispersal activity, distribution, and isolation of the species were affected only by the different climatic zones (Shiferaw, 2017), and different regions or continents (Tuda et al., 2014).

The infestation rates of different pests varied according to abiotic factors such as humidity and temperature ranges, which could affect their population abundance and distribution (Isikber et al., 2016). However, Malaysia is located in a tropical region with an equatorial climate of uniformly high temperatures and relative humidity, and heavy rainfall throughout the year. Since the sampling areas and distances involved are small (maximum distance of $650 \mathrm{~km}$ apart), the abiotic factors are relatively similar between the sampling locations. As such, the temperature and humidity conditions are standardized and well regulated under warehouse conditions in this study.

The rationale behind the three-month study period is significant because $O$. surinamensis would complete its lifecycle (one generation) after three months by producing more than 2000 individuals of progeny at certain temperature and moisture conditions (Lessard et al., 2005a). This species is also known as a cosmopolitan insect due to its high reproduction rate (Arthur, 2001). Previous studies had reported that other pests such as mites and psocids would decrease the seed germinability, causing kernel damage and weight loss after three months of infestation by the primary pests such as beetles (Sitophilus sp., Tribolium sp., Oryzaephilus sp.) and moths (Plodia sp.) (Stejskal et al., 2014). The damaged kernels would then be consumed by $O$. surinamensis, as a secondary pest.

The Klang warehouses showed the highest abundance of $O$. surinamensis for the entire three months, followed by those of Pasir Gudang and Seberang Prai. The results were significantly different between populations from the three zones, at $\mathrm{p}<0.05(\mathrm{p}=0.00)$. This might be due to the prevailing poor sanitary conditions in the warehouses in terms of diligent cleaning process, as well as a thorough and detailed inspection schedule of the warehouses. Under suitable moisture and moderate heat conditions, the dust, chaff, mold and damaged grains would provide ample food sources for the secondary pests such as O. surinamensis (Lord, 2008; Aulicky et al., 2015).

However, the practice of mixing different rice varieties in one warehouse would also enhance the severity and infestation rate of the pest (Nadeem et al., 2011; Upadhyay and Ahmad, 2011). In this study, the quantity of rice stock and the variety of rice stored differed among the warehouses, and these two factors could well be contributing to the different amounts of stored grains being damaged and the percentage of pest abundance observed, where the highest infestation rate was recorded in Klang (Khidir personal communication). A study by Khan and Halder (2012) proved that the mean number of rice weevils emerging after 22 weeks of infestation in six varieties of rice differed significantly, mainly due to the rice aroma, and also the chalkiness and the amylose content of the different rice varieties (Reddy and Bhotmange, 2014). However, our own observations in this study were not conclusive due to lack of information on the different rice varieties stored in each warehouse.

The different patterns of pest abundance exhibited in each of the warehouses during the three-month study period showed significant differences between months, $p<0.05$ ( $p$ value $=0.00-0.011$ ) in all the locations. This was probably due to various factors, namely the inconsistent and irregular fumigation schedule, the residual pests from the old rice stock, unclean storage bags and insanitary warehouse conditions (Ogebegbe and Edoreh, 2014). Toews and Subramanyam, (2003), noted that the efficacy of pesticide application could be reduced in an unclean environment, thus, increasing the rate and severity of infestation.

Data on the spatial and temporal distribution of the pest species could provide very valuable information in monitoring the storage pests, especially for the main ones, which are the moth and beetle species (Arbogast et al., 2000a, b; Sciarretta et al., 2001). The different areas of commodities appear to have different species, population and infestation rates (Lazzari et al., 2010). Our results differed from the findings of Trematerra (2004) who reported that the spatial distribution of the Apple sawfly population was clumped due to behavioral or environmental effects in distinct parts of the State of Santa Catarina rice facilities. Since the environmental factors were standardized in our study, we surmised that the behavior of $O$. surinamensis played the most important role in its distribution pattern. Multiple studies have also reported that the insect pests of stored products have spatially and temporally patchy distributions inside built structures (Arbogast et al., 2000a; Nansen et al., 2004) and including around the outside of the structures (Campbell et al., 2002). Based on the results presented (Table 1 and Figures 5a to 5c), several population patches were found to show aggregated and isolation patterns on the contour map. This might be due to the rapidly depleting rice stock because of a rapid turnover or in-out inventory of the storage, which referred to the exportation and importation of rice stacks among the warehouses between zones, especially in Klang and Johore Bahru. Such an inventory could well be one of the possible reasons for the wide and rapid spread of this pest species.

As observed in our study and also noted by Campbell et al. (2006), O. surinamensis, being a poor flyer, was relatively unaffected by differences in land-cover and land use, or by the placement and location of the rice stacks in the warehouses. However, physical and chemical environmental changes that occurred during pesticide applications could affect the pest movements around the warehouses while in search of suitable sites for mating and egg laying (Jian, 2019). Such behavioural changes could affect their distribution pattern significantly (Guedes et al., 2000; Jian, 2019). 
Our results indicated that the $\mathrm{X}$ and $\mathrm{Y}$ warehouses at Seberang Prai distinctly showed a regular distribution of the pest population, although not significantly supported by the statistical analysis, $\mathrm{p}>0.05(\mathrm{p}=0.3462-0.9103)$ and $\mathrm{I}_{\mathrm{a}}=0.769$ 0.945). High mobility and adaptive behaviour, and the ability to attack packaged food also enabled $O$. surinamensis to live freely in the warehouse at high population abundance under suitable environment and with abundant food source (Beckel et al., 2007). Our further observations showed that the volume of stored rice was higher in the $\mathrm{X}$ and $\mathrm{Y}$ warehouses compared to the $\mathrm{Z}$ warehouse and the other warehouses in the Klang and Pasir Gudang areas, due to the inactive in-out inventory activities (turnover). Since the main reason for insect movement is to find new food sources, the larger rice stocks in the warehouse would induce more active and free movements of $O$. surinamensis to avoid clumping and overcrowding at any one place, and such active movements would result in a regular distribution pattern (Jian, 2019). In contrast, the $\mathrm{Z}$ warehouses had much lower rice stock, and $O$. surinamesis moved less randomly due to lack of preference in food source and thus, they became aggregated at their favorable position (Jian, 2009).

Conclusion: This study has successfully reported the population abundance, spatial and temporal distribution of $O$. surinamensis pest of stored rice from three different zones (south, north and central parts of Peninsular Malaysia) under well-regulated warehouse conditions. The abundance of $O$. surinamensis was found to be highest in the Klang District of Selangor at $69 \%$, followed by the Pasir Gudang area of Johor Bharu in the southern zone at 27\%, and the Seberang Prai, Penang in the northern zone at $4 \%$, during the three-month study period. The patterns of the species abundance also showed significant differences between months, $\mathrm{p}<0.05$ ( $\mathrm{p}$ value $=0.00-0.011)$ in all the warehouses. The environmental factors that could be associated with the population abundance and distribution pattern of the rice pest could be due to poor sanitation and inconsistency in the fumigation schedule.

The spatial and temporal distribution of $O$. surinamensis showed either aggregated or regularly distributed patterns in all the warehouses. However, the distribution of the pest species was significantly aggregated in many of those warehouses which had lower volume of the rice stock due to the less active in-out storage inventory. Likewise, the reverse is true for the regularly distributed pattern of the pest population in the other two warehouses ( $\mathrm{X}$ and $\mathrm{Y}$ ), although this surmise is not significantly supported by the statistical analysis. These findings are regarded as fundamental data and are very valuable and significant in structuring and implementing pest management strategies for pests of stored grain products, such as $O$. surinamensis. Several recommendations are suggested, viz. frequent and regular cleaning process, scheduled to coincide with the timing of fumigation and proper inventory to regulate the volume of rice stock in storage and good general housekeeping in the respective warehouses.

Conflict of Interest: The authors declare that there is no conflict of interests regarding the publication of this article.

Acknowledgments: The authors would like to express our special gratitude to Mr. Mohd Aliff Shamsuniam Bin Mansur and Mr. Khidir Bahari, Padi Beras Nasional Berhad (BERNAS) for their kind cooperation and sampling permission and to Miss Nur Atikah Abd Rahim for helping us in the insect collection. The authors would like to thank Maimon Abdullah for her kind editing and critical comments of the draft copy of this paper. This project was supported by the UKM Grant noTP-K013317.

\section{REFERENCES}

Arbogast, R.T., P.E. Kendra, R.W. Mankin and J.E. McGovern. 2000a. Monitoring insect pests in retail stores by trapping and spatial analysis. J. Econ. Entomol. 93:1531-1542.

Arbogast, R. T., P. E. Kendra, D. K. Weaver and B.H. Subramanyam. 2000b. Phenology and spatial pattern of Typhaea stercorea (Coleoptera: Mycetophagidae) infesting stored grain: estimation by pitfall trapping. $J$. Econ. Entomol. 93:240-251

Aulicky, R., V. Stejskal, Z. Kucerova and P. Trematerra. 2015. Trapping of internal and external feeding stored grain beetle pests with two types of pitfall traps: a twoyear field study. Plant Prot. Sci. 52:45-53.

Barnes, J. K. 2002. Saw-toothed grain beetle. Arthropod Museum Notes No.7 University of Arkansas of Agriculture Department of Entomology.

Beckel, H. D. S., I. Lorini and S. Lazzari. 2007. Rearing method of Oryzaephilus surinamensis (L.)(Coleoptera, Silvanidae) on various wheat grain granulometry. Rev. Bras. Entomol. 51:501-505.

Campbell, J.F., G.P. Ching'oma, M.D. Toews and S.B. Ramaswamy. 2006. Spatial distribution and movement patterns of stored-product insects. In Proceedings of the 9th International Working Conference on Stored Product Protection. 15:361-370.

Campbell, J. F. M.A. Mullen and A.K. Dowdy. 2002. Monitoring stored-product pests in food processing plants with pheromone trapping, contour mapping, and mark- recapture. J. Econ. Entomol. 95:10891101.

Ferrer, J. 1995. A key to the Flour beetles of the genus Tribolium Macleay in Sweden (Coleoptera, Tenebrionidae), with distributional notes. Entomol. Tidskr. 116:123-126. 
Guedes, N.M.P., R.N.C. Guedes, G.H. Ferreira and L.B. Silva, 2009. Flight take-off and walking behavior of insecticide-susceptible and-Resistant strains of Sitophilus zeamais exposed to deltamethrin. Bull. Entomol. Res. 99:393-400

Hashem, M. Y., S. S. Ahmed, M.A. El-Mohandes and M.A. Gharib. 2012. Susceptibility of different life stages of saw-toothed grain beetle Oryzaephilus surinamensis (L.) (Coleoptera: Silvanidae) to modified atmospheres enriched with carbon dioxide. J. Stored Prod. Res. 48:4651.

Hernandez Nopsa, J. F., G.J. Daglish, D.W. Hagstrum, J.F. Leslie, T.W. Phillips, C. Scoglio, S. Thomas-Sharma, G.H. Walter and K.A. Garrett. 2015. Ecological networks in stored grain: Key postharvest nodes for emerging pests, pathogens, and mycotoxins. BioScience. 65:9851002.

Highland, H.A. 1991. Protecting packages against insects, In: J. R. Gorham (ed.), Ecology and Management of FoodIndustry Pests, FDA Technical Bulletin 4. Association of Official Analytical Chemists, Arlington, Virginia. pp. 345-350.

Işikber, A.A., H. Tunaz, İ. Doğanay and M.K. Er. 2016. The infestation rate and abundance of insect pests on stored corn in different climatic zones of Turkey. Turk. Bull. Entomol. 6:349-356.

Jian, F. 2019. Influences of stored product insect movements on integrated pest management decisions. Insects. 10:100.

Jian, F. and D.S. Jayas. 2009. Detecting and responding to resource and stimulus during the movements of Cryptolestes ferrugineus adults. Food Bioprocess Technol. 2:45-56.

Khan, H.R. and P.K. Halder. 2012. Susceptibility of six varieties of rice to the infestation of rice weevil, Sitophilus oryzae (L.) (Coleoptera: Curculionidae). Dhaka University J. Biol. Sci. 21:163168.

Lazzari, M., A. Loperte and A. Perrone. 2010. Near surface geophysics techniques and geomorphological approach to reconstruct the hazard cave map in historical and urban areas. Adv. Geosci. 24:35-44.

Lord J.C. 2008. Stored Grain and Flour Insects and Their Management. In: Capinera J.L. (eds) Encyclopedia of Entomology. pp.3586-3593. Springer, Dordrecht. https://doi.org/10.1007/978-1-4020-6359-6_4421 pp.3586-3593.

Mowery, S.V., M. A. Mullen, J.F. Campbell and A.B. Broce. 2002. Mechanisms underlying sawtoothed grain beetle (Oryzaephilus surinamensis [L.]) (Coleoptera: Silvanidae) infestation of consumer food packaging materials. J. Econ.95:1333-1336.
Nadeem, S., M. Hamed and M. Shafique. 2011. Feeding preference and developmental period of some storage insect species in rice products. Pak. J. Zool. 43:79-83.

Nansen, C., T.W. Phillips, M.N. Parajulee and R.A. Franqui. 2004. Comparison of direct and indirect sampling procedures for Plodia interpunctella in a maize storage facility. J. Stored Prod. Res. 40:151-168.

Ogebegbe, A.B.O., and J.A. Edoreh. 2014. An Evaluation of Infestation of Insect Pests of Flours in Benin City, Edo State, Nigeria. J. Applied Sci. Environ. 18:487-494.

Page, R.D. 2001. TreeView. Glasgow University, Glasgow, UK.

Ratnasingham, S.and P.D. Hebert. 2007. BOLD: The Barcode of Life Data System (httpp://www. barcodinglife. org). Mol. Ecol. Notes. 7:355-364.

Reddy, D.K., and M.G. Bhotmange. 2014. Viscosity of starch: A comparative study of Indian rice (Oryza sativa L.) varieties. Int. Appl. Eng. Res. 4:397- 402.

Reichmuth, C. 2000. Biological control in stored product protection. IOBC WPRS BULLETIN. 23:11-24.

Rossiter, L. C., R.V. Gunning and H.A. Rose. 2001. The use of polyacrylamide gel electrophoresis for the investigation and detection of fenitrothion and chlorpyrifos-methyl resistance in Oryzaephilus surinamensis (Coleoptera: Silvanidae). Pestic. Biochem. Phys. 69:27-34.

Sciarretta, A., P. Trematerra and J. Baumgartner. 2001. Geostatistical analysis of Cydia funebrana (Treitschke) (Lepidoptera: Tortricidae) pheromone trap catches at two spatial scales. Am. Entomol. 47:138-147.

Semeaoa, A.A., J.F, Campbell, J.M.S, Hutchinson, R.J. Whitwortha and P.E. Sloderbeck, 2014. Spatio-temporal distribution of stored-product insects around food processing and storage facilities. Agric. Ecosys. Environ.165:151-162.

Shah, M.A. and A.A. Khan. 2014. Imaging techniques for the detection of stored product pests. Appl. Entomol. Zool. 49:201-212.

Shiferaw, T., and E. Jigjiga. 2017. Occurrence of Stored Grain Insect Pests in Traditional Underground Pit Grain Storages of Eastern Ethiopia. J. Biol. Agric. 7:1-4.

Sittisuang, P. and O. Imura. 1987. Damage of rough and brown rice by four stored-product insect species. Appl. Entomol. Zool. 22:585-593.

Stejskal, V., R. Aulicky and Z. Kucerova. 2014. Pest control strategies and damage potential of seed-infesting pests in the Czech stores-a review. Plant Prot. Sci. 50:165-173.

Syarifah Zulaikha, S. A., M. Halim, A.R. Nor Atikah and S. Yaakop. 2018. Diversity and Abundance of Storage pest in Rice Warehouses in Klang, Selangor, Malaysia. Serangga. 23:89-98.

Tamošiūnas, R., A. Valiuškaitè, L. Jukna, K. Tamošiūnas and A.F. Žiogas. 2015. Spatial 
distribution patterns of apple sawfly populations in two differently managed commercial apple orchards. Zemdirbyste-Agriculture. 102:73-80

Toews, M. D., and B. Subramanyam. 2003. Sanitation in grain storage and handling. Marcel Dekker, Inc. New York Basel.

Trematerra, P. and J. Throne. 2012. Insect and mite pests of durum wheat. Durum wheat, chemistry and technology, Second Edition. AACC International Inc., St. Paul, MN, USA. pp.73-83.
Tuda, M., K. Kagoshima, Y. Toquenaga and G. Arnqvist. 2014. Global genetic differentiation in a cosmopolitan pest of stored beans: effects of geography, host-plant usage and anthropogenic factors. PLoS One. 9(9): e106268.

Upadhyay, R.K., and S. Ahmad. 2011. Management strategies for control of stored grain insect pests in farmer stores and public warehouses. World J. Agric. Sci. 7:527549. 